\title{
DAILY RHYTHMS IN SOCIAL ACTIVITIES OF THE HARVESTER ANT, POGONOMYRMEX BADIUS*
}

\author{
By Deborah M. Gordon \\ Department of Zoology, \\ Duke University, \\ Durham, N.C. 27706
}

Daily cycles in behavior are well known throughout the animal kingdom. There is some evidence that the activities of ant colonies are temporally organized so that, at a given time of day, a certain set of tasks is done. This study explores that possibility by examining temporal patterns in the social behavior of the harvester ant, Pogonomyrmex badius. Such patterns should be distinguished from circadian rhythms to which conform endogenous, physiological events exhibited by individual animals (e.g. McCluskey 1958 and 1965). The present study is concerned with daily rhythms in social activities performed by groups of ants. Two questions are addressed: 1) Are certain tasks performed at characteristic times of day? 2) How do activity rhythms vary among different colonies?

There have been many studies of daily temporal patterns in the overall activity levels of ant colonies, measured as the numbers of ants entering or leaving the nest (Levieux and Diomande 1978a, Hunt 1974, Hansen 1978, Van Pelt 1966), or the numbers of ants in certain areas for specified durations (Janzen 1967, Levieux and Diomande 1978b, Levieux 1979a and 1979b, Golley and Gentry 1964). Temporal patterns of overall activity level are well documented for several Pogonomyrmex species (Hölldobler 1970 and 1976a, Whitford and Ettershank 1975, Whitford et al. 1976). Some authors have described temporal patterns of selected social activities of various ant species (Möglich and Alpert 1979, Janzen 1967, Levieux and Diomande 1978a and 1978b), including Pogonomyrmex (Willard and Crowell 1965, Hölldobler 1976b). But, except for Hölldobler's (1976b) study of mating activity, the cited work presents no systematic data on temporal patterns in behavior other than entering and leaving the nest. In some recent field studies of

*Manuscript received by the editor November 21, 1983 
Pogonomyrmex behavior, I found activity rhythms of various colony tasks (Gordon 1983b and 1983c).

$P$. badius has received much less attention than other Pogonomyrmex species, perhaps because it is geographically isolated from them. Nevertheless, the scanty literature on P. badius behavior contains some descriptive reports that suggest the existence of activity rhythms in this species as well (Van Pelt 1966, Hangartner et al. 1970). The present study was made in the laboratory. In this way, activity rhythms could be investigated more systematically than would be possible in a field study.

\section{METHODS}

Four queenright colonies (colonies 1, 2, 3, and 4), each containing 300-600 workers, were observed for 30 days from March 1, 1983 through April 2, 1983. Colonies were kept in open, soil-filled terraria, and fed Bhaktar-Whitcomb (1970) diet or chopped mealworms. The study colonies had all been kept in the laboratory for about one year. They were chosen for the study because they had been consistently active and healthy since being brought into the laboratory. The laboratory temperature was maintained at $27^{\circ} \mathrm{C}\left( \pm 1^{\circ}\right)$.

Observations of each colony were made 5 times daily, once in each of five 100-minute time periods, as follows: Time period 1 (TP1), 9:50-11:30; TP2, 11:30-13:20; TP3, 13:20-14:50; TP4, 14:50-16:30; TP5, 16:30-18:10, and usually in the middle of the time period at the following five times; 10:40, 12:20, 14:00, 15:40 and 17:20. Overhead fluorescent lights in the laboratory were on from 7:30 to 23:00. A lamp with a 60 watt bulb was placed from 30 to 50 $\mathrm{cm}$ above each colony as a heat source. These lamps were illuminated daily from 11:30 until 16:30. Thus, during the first and last observations, room lights but not individual lamps were on; during the 2 nd -4 th time periods, individual lamps were on as well. Temperatures on the terraria surfaces, both under the individual lamps and at other points on the opposite side of the tanks, were measured with a thermistor (Yellow Springs Instrument Co. \#408). Temperature measurements were made in the terraria of the four study colonies and also in those of four other colonies maintained in an identical manner. The colonies were fed every other day immediately after the 12:20 observation. 
All behavior observed taking place outside the nest was classified as one of five activities: Foraging, Nest Maintenance, Patrolling, Midden Work, and Convening (Table 1). For each nest, observations noted the numbers of ants in each of the five activities. The sum of the five numbers is the total number of ants observed outside the nest. A total of 600 observations were made on the four colonies.

The data were analysed by profile analysis (Timm 1975) to determine whether the numbers of ants engaged in particular activities depend significantly on both activity and time of day. Since the times of foraging corresponded so obviously to the time the ants were fed, foraging was not considered in the analysis.

Profile analysis is a series of 3 multivariate analyses of variance (manova), described in detail below. Factors considered were colony and date as main effects. The hypothesis that the intercept was significantly greater than zero was also considered as a main effect. Date was considered to be a random effect. Each analysis was made using the data from all 4 colonies, then repeated for each colony separately. Data were log-transformed to ensure that ratios, not numbers of ants, were used in the analysis, making it possible to compare colonies of different sizes.

\section{RESULTS}

The first multivariate analysis of variance tested for significant differences in overall activity among time periods. For each day of observation of a given colony, a new variable was created for each time period by adding the (log-transformed) numbers of ants doing nest maintenance, midden work, convening and patrolling. Four differences between time periods were used as observation variables (Table 2, top).

The results (Table 2 ) show that colonies are significantly more active in TP2 than in TP1, in TP3 than in TP4, and in TP4 than in TP5. The overall activity level of the colony has a peak in the middle of the day.

The next manova tested for significant differences in the numbers of ants engaged in each activity, summed over all time periods. A new variable was created by adding, over all five time periods for each day of observation of a particular colony, the (logtransformed) number of ants doing each activity. Three differences 


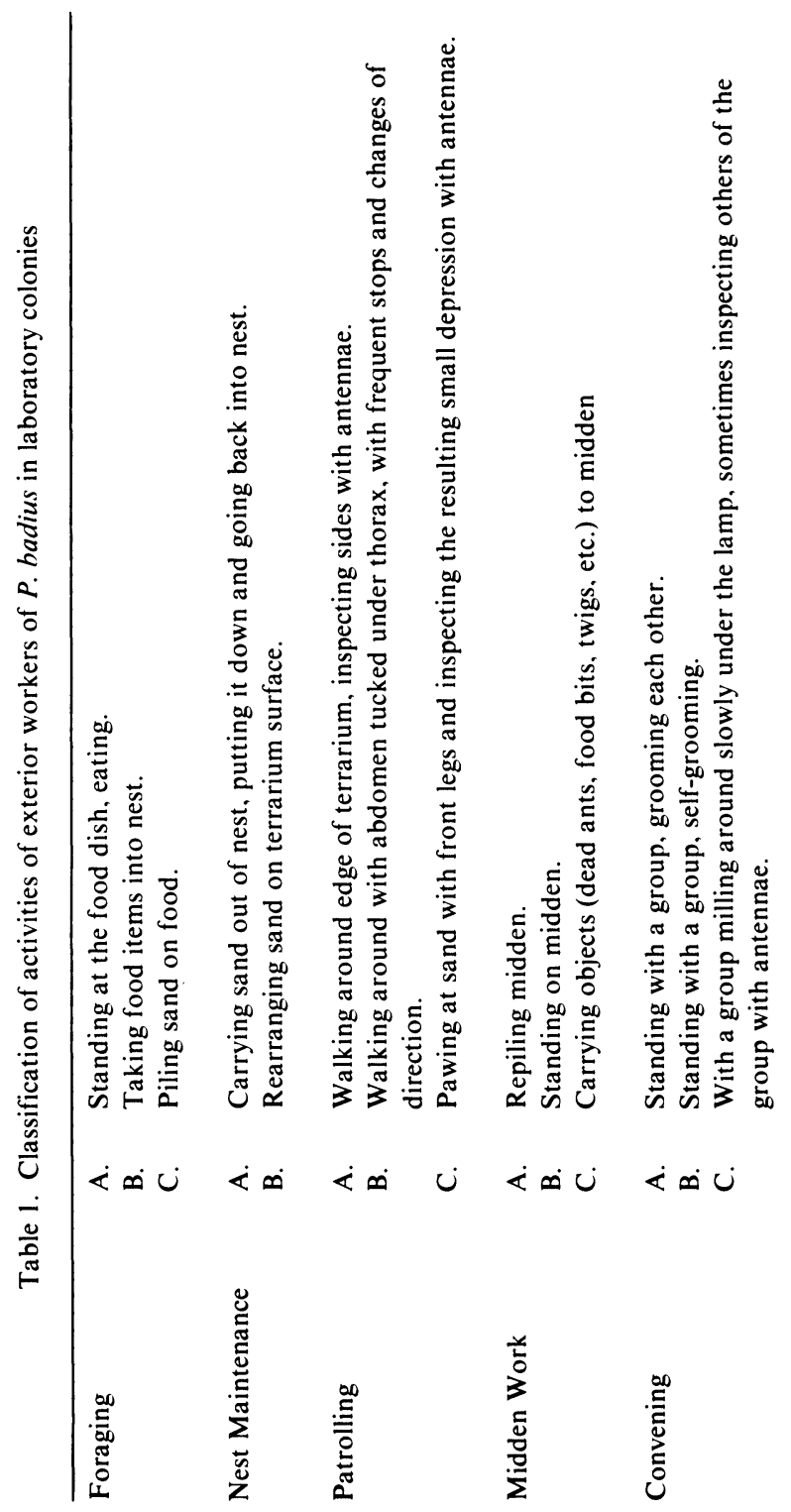


between activities were used as observation variables (Table 2 , middle). The results (Figure 1 for foraging, and Table 2 for the other activities) show that the activities may be ranked as follows, according to the numbers of ants engaged in each one: Midden work $>$ patrolling $>$ convening $>$ nest maintenance $>$ foraging.

Figure 1 shows the activity rhythms of each of the four study colonies. The third manova tested whether some pairs of activities are performed by significantly different numbers of ants when the activities are compared at particular times (Table 2, bottom). Significant differences mean that the rate at which the colony invests workers in a particular task depends both on the task and on the time of day. The results (Table 2) may be best understood by inspecting Figure 1. For example, keeping in mind that the data are log-transformed, activity-time period difference number 4 (Table 2) can be stated as follows: The ratio of number of ants doing midden work to number convening in time period 1 is significantly greater than the same ratio in time period 3. In other words, from TP1 to TP3 convening increases faster, or has a steeper slope, than does midden work. This difference is especially clear in the graph for colony 4 .

The overall results in Table 2 lead to the following conclusions about slope differences in Figure 1: Convening rises to a peak in TP2, increasing more rapidly than midden work, then declines more rapidly than either midden work or patrolling. In general, patrolling declines throughout the day while nest maintenance increases. The fact that activity-time period differences 7,8 , and 9 are not significant indicates that all 4 activities change at about the same rate from TP3 to TP4.

The colony main effect was significant $(p>0.05)$ for time period differences 1, 2, and 4, for activity differences 1,2 , and 3 , and for activity-time period differences $1,4,5,6$, and 10 . The date main effect was significant for time period difference 3 , activity difference 3 , and activity-time period differences $3,7,8$, and 11 .

Mean temperatures of the terraria surfaces are shown in Figure 2, as a function of the time of day.

\section{Discussion}

The behavior of a colony clearly is temporally patterned. It has frequently been suggested that, in harvester ants, overall activity 
Table 2. Results of profile analysis.

Results of test for differences in activity level by time period are shown at the top of the table: for test for differences in number of ants in each activity, middle of the table; for test for activity-time period differences (parallelism test), bottom of the table. Data are log-transformed. Symbols used are ${ }^{* *} p>0.01 ; *, p>0.05$; \#. marginal significance. $\mathrm{TP}=$ time period; $\mathrm{MW}=$ midden work: $\mathrm{CN}=$ Convening; $\mathrm{PT}$ = patrolling: $\mathrm{NM}=$ nest maintenance.

Source:

Intercept as main effect

$(\mathrm{DF}=29)$
TP1 - TP2
TP2 - TP3
TP3 - TP4
TP4 - TP5

Midden Work - Convening

Convening - Patrolling

Patrolling - Nest Maintenance

1. TP1.MW - TP1.CN - TP5.MW + TP5.CN

2. TP1.CN - TPI.PT - TP5.CN + TP5.PT

3. TP1,PT - TPI,NM - TP5,PT + TP5,NM

4. TP1,MW - TP1,CN $-\mathrm{TP} 3, \mathrm{MW}+\mathrm{TP} 3, \mathrm{CN}$

5. TP1,CN - TP1.PT - TP3,CN + TP3,PT

6. TP1.PT - TPI.NM - TP3,PT + TP3,NM

7. TP3,MW - TP3,CN - TP4, MW + TP4,PT

8. TP3,CN - TP3,PT - TP4,CN + TP4,PT

9. TP3.PT - TP3.NM - TP4.PT + TP4.NM

10. TP4.MW - TP4.CN $-\mathrm{TP} 2, \mathrm{MW}+\mathrm{TP} 2, \mathrm{CN}$

11. TP4.CN - TP4.PT - TP2,CN + TP2,PT

12. TP4,PT - TP4,NM - TP2,PT + TP2,NM

13. TP4,MW - TP4,NM - TP2,MW + TP2,NM

14. TP3,PT - TP3,NM - TP5,PT + TP5,NM

15. TP2,PT - TP2,NM - TP5,PT + TP5,NM
Overall

(All 4 colonies)

$\begin{array}{cc}F & \begin{array}{c}\text { Mean } \\ \text { Difference }\end{array} \\ 346.4^{* *} & -1.24 \\ 3.9 & -0.07 \\ 17.8^{* *} & 0.19 \\ 411.5^{* *} & 1.19 \\ & \\ 206.6^{* *} & 1.43 \\ 175.8^{* *} & -1.37 \\ 256.9^{* *} & 2.55 \\ & \\ 8.6^{* *} & -0.19 \\ 9.5^{* *} & 0.17 \\ 48.1^{* *} & 0.25 \\ 115.4^{* *} & 0.59 \\ 132.9^{* *} & -0.60 \\ 13.5 & 0.11 \\ 2.9 & -0.06 \\ 0.5 & 0.03 \\ 5.7^{*} & 0.06 \\ 51.9^{* *} & 0.21 \\ 28.6^{* *} & -0.21 \\ 10.5^{* *} & -0.12 \\ 11.2^{* *} & -0.12 \\ 26.9^{* *} & 0.14 \\ 32.9^{* *} & 0.19\end{array}$

level (sometimes called foraging activity) is related to temperature (Rogers 1974, Whitford and Ettershank 1975, Bernstein 1979). My results support this suggestion. During TP2 through TP4, when the individual lamps were on and the soil temperatures were highest (Figure 2), colonies were significantly more active than they were during time periods 1 and 5 . Temperatures in the field often become so high that ants are inactive from midday until early evening. In the 
Table 2. (continued).

18

$\begin{array}{cccc}\mathrm{F} & \begin{array}{c}\text { Mean } \\ \text { Difference }\end{array} & \mathrm{F} & \begin{array}{c}\text { Mean } \\ \text { Difference }\end{array} \\ 203.8^{* *} & -1.65 & 106.9^{* *} & -1.1 \\ 0.3 & 0.04 & 7.9^{* *} & 0.15 \\ 6.1^{* *} & 0.18 & 13.5^{* *} & 0.27 \\ 422.9^{* *} & 2.05 & 68.8^{* *} & 0.89 \\ & & & \\ 152.9^{* *} & 2.07 & 86.6^{* *} & 1.55 \\ 117.9^{* *} & -1.74 & 17.9^{* *} & -0.69 \\ 75.1^{* *} & 1.86 & 152.7^{* *} & 2.02 \\ & & & \\ 18.1^{* *} & -0.49 & 1.1 & -0.14 \\ 12.9^{* *} & 0.39 & 1.6 & 0.16 \\ 22.7^{* *} & 0.31 & 29.1^{* *} & 0.36 \\ 40.9^{* *} & 0.63 & 11.6^{* *} & 0.35 \\ 40.3^{* *} & -0.63 & 15.9^{* *} & -0.36 \\ 1.3 & 0.05 & 19.8^{* *} & 0.26 \\ 1.7 & 0.20 & 1.8 & -0.07 \\ 0.5 & 0.05 & 0.04 & 0.01 \\ 3.5 & 0.08 & 2.0 & 0.06 \\ 13.9^{* *} & 0.23 & 51.9^{* *} & 0.25 \\ 13.4^{* *} & -0.24 & 20.8^{* *} & -0.18 \\ 1.6 & -0.08 & 16.9^{* *} & -0.22 \\ 2.4 & -0.10 & 12.1^{* *} & -0.15 \\ 23.9^{* *} & 0.26 & 3.3 & 0.10 \\ 14.6^{* *} & 0.26 & 17.9^{* *} & 0.26\end{array}$

16

13
By Colony 

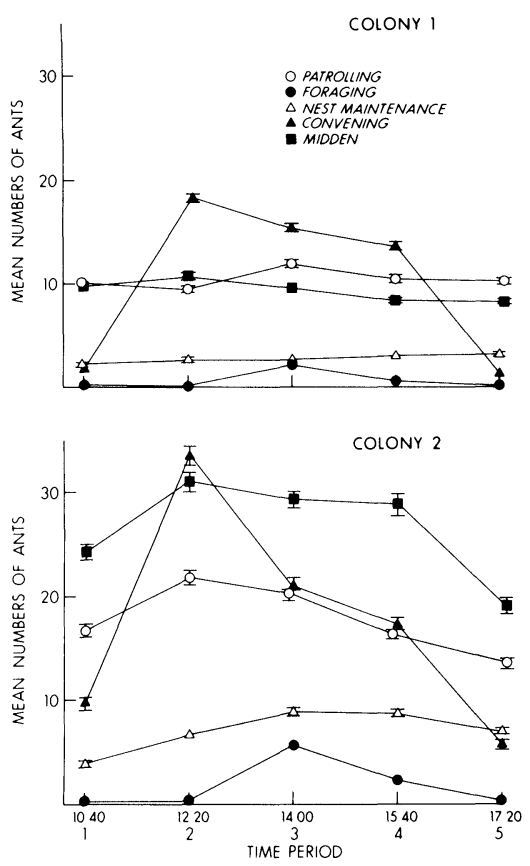

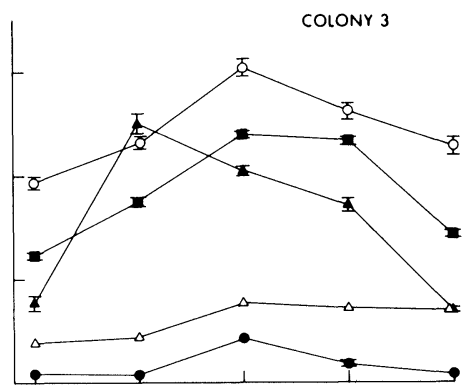

COLONY 4

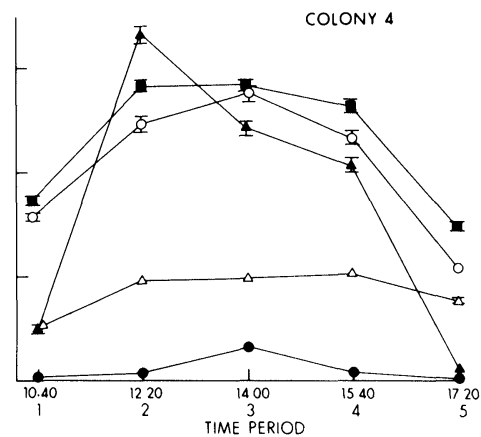

Figure 1. Daily activity rhythms.

The mean numbers of ants engaged in each activity are plotted as a function of time of day. Times shown are the usual observation times. Error bars show standard error of the mean. No error bar is present when the size of the error bar was smaller than that of the symbol for a point in the graph.

as temperature and food availability. In $P$. badius, the five activities described here are performed by four distinct groups of ants (midden work and patrolling are done by the same individuals) (Gordon 1983d). Whether there are intrinsic physiological rhythms causing these different groups to be active outside the nest in different numbers, depending on time of day, is a question still to be explored.

Temporal patterns in overall activity level are known to exist in many species of ants. Further research on such species may reveal more detailed patterns of particular activities. Cognizance of such patterns is relevant to the design of further behavioral experiments, 


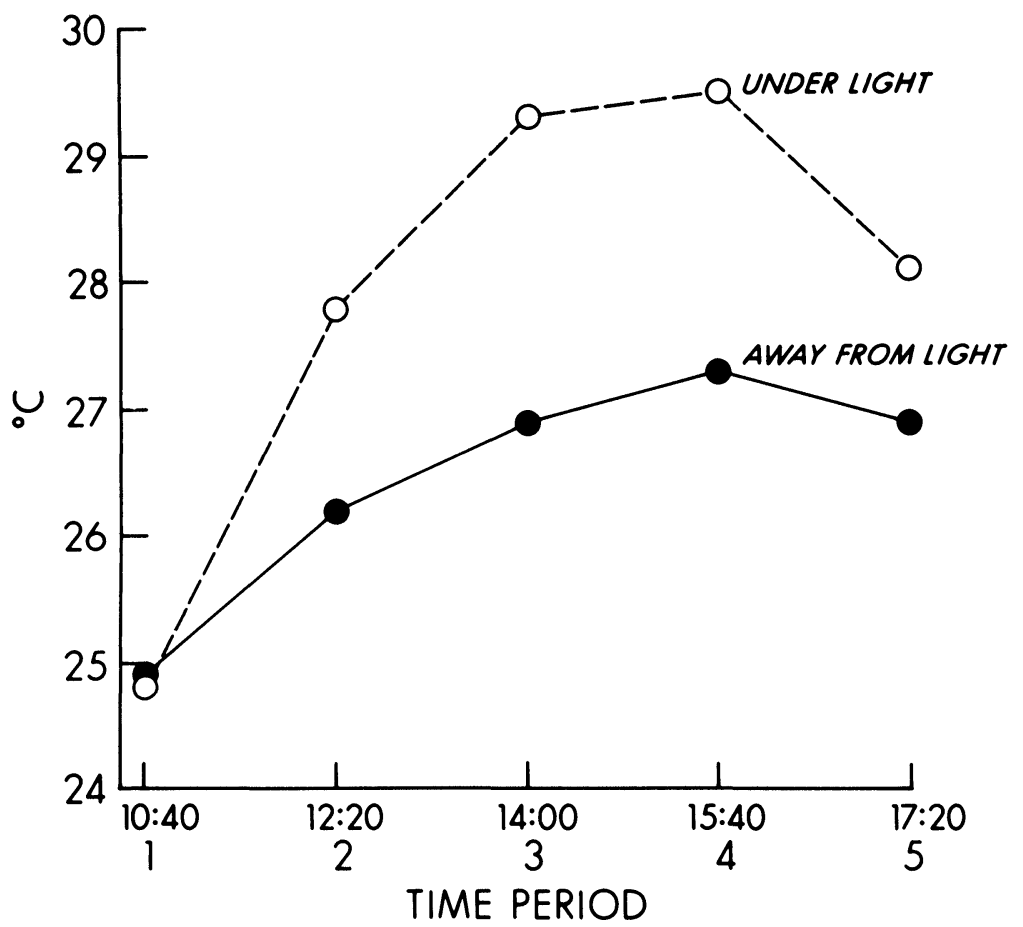

Figure 2.

Mean temperature on the soil surface, both directly under the lamp and on the opposite side of the tank, plotted as a function of the times of measurement.

because results may be affected by the times of day at which data are collected (e.g., Gordon 1983d and 1983b).

The results show that, though colonies are similar to one another, distinct colonies have distinct activity rhythms (Figure 1). Thus, intercolony variation should also be taken into account when designing experiments. The main point of this study, then, is not that the activity rhythms of $P$. badius are those shown in Figure 1, but that each colony exhibits some temporal pattern of activities. In every colony, certain tasks are undertaken at characteristic times. Clearly, we need to consider temporal patterns when we endeavor to understand the social organization of the ant colony. 


\section{ACKNOWLEDGEMENTS}

I am grateful to R. Shaw and D. S. Burdick for statistical advice, to T. Williams for valuable discussions, to B. Hölldobler for comments on the manuscript, and to J. Gregg and R. Palmer for help with all stages of the project.

\section{RHFERENCES}

Bernstein, R. A.

1979. Schedules of foraging activity in species of ants. J. Anim. Ecol. 48: 921-930.

Bhaktar. A. W. AND W. Whitcomb.

1970. Artificial diet for rearing various species of ants. Fla. Entomol. 53(4): 229-232.

Golliey, F. B. And J. B. Gentry.

1964. Bioenergetics of the southern harvester ant. Pogonomyrmex hadius. Ecol. 45: 217-225.

GORDON, D. M.

1983a. The dependence of necrophoric response to oleic acid on social context in the harvester ant, Pogonomyrmex hadius. J. Chem. Ecol. 9(1): 105-111.

1983b. The relation of recruitment rate to activity rhythms in the harvester ant, Pogonomyrmex harhatus (F. Smith). J. Kans. Ent. Soc. 56(3): 277-285.

1983c. Species-specific patterns in the social activities of harvester ant colonies (Pogonomyrmex). Insectes Sociaux. In press.

1983d. The organization of role behavior in colonies of the harvester ant, Pogonomyrmex hadius. In preparation.

Hangartner, W., J. M. Reichison, and E. O. Wil.son.

1970. Orientation to nest material by the ant Pogonomyrmex hadius. Anim. Behav. 18(2): 331-334.

HANSEN, S. R.

1978. Resource utilisation and coexistence of three species of Pogonomyrmex ants in an upper Sonoran grassland community. Oecologia 35: 109-117.

HOILLDOBLER, B.

1970. Steatoda fulva (Theridiidae), a spider that feeds on harvester ants. Psyche, 77: 202-208.

1976a. Recruitment behavior, home range orientation, and territoriality in harvester ants. Pogonomyrmex. Behav. Ecol. Sociobiol. 1: 3-44.

1976b. The behavioral ecology of mating in harvester ants (Pogonomyrmex). Behav. Ecol. Sociobiol. 1(4): 405-423.

HINT, J. H.

1974. Temporal activity patterns in two competing ant species. Psyche, 81: 237.242. 
JANZEN, D. H.

1967. Interaction of the bull's horn acacia (Acacia cornigera L.) with an ant inhabitant (Pseudomyrmex ferruginea $\mathrm{F}$. Smith) in eastern Mexico. Univ. Kansas Sci. Bull. 47(6): 315-558.

LeVIFI'X, J.

1979a. La nutrition des fourmis granivores. III. Cycle d'activité et régime alimentaire en saison des pluies de Brachyponera senaarensis fluctuations saisonières. Insectes Sociaux 26(3): 232-239.

1979b. La nutrition des fourmis granivores. IV. Cycle d'activité et régime alimentaire de Messor galla et de Messor (=Cratomyrmex) regalis. en saison des pluies fluctuations annuelles. Insectes Sociaux 26(4): 279-294.

Levifi'x, J. AND T. Diomande.

1978a. La nutrition des fourmis granivores. I. Cycle d'activité et régime alimentaire de Messor galla et de Messor (=Cratomyrmex) regalis. Insectes Sociaux 25(2): 127-139.

1978b. La nutrition des fourmis granivores. II. Cycle d'activité et régime alimentaire de Brachıponera senaarensis (Mayr). Insectes Sociaux 25(3): 187-196.

MCCLI'SKFY, E.

1958. Daily rhythms in male harvester and argentine ants. Science 128: 536-537.

1965. Circadian rhythms in male ants of five diverse species. Science 150 : 1037-1039.

Mogglich, M. and G. D. Al.pert.

1979. Stone-dropping by Conomyrma hicolor-a new technique of interference competition. Behav. Ecol. Sociobiol. 6: 105-113.

Rogers, L. E.

1974. Foraging activity of the western harvester ant in the shortgrass plains ecosystem. Env. Entomol. 3(3): $420-424$.

Tімм, N. H.

1975. Multivariate anal!'sis. Monterey, CA: Brooks/Cole Publishing Co.

Van Peit, A. F.

1966. Activity and density of old-field ants of the Savannah River Plant, South Carolina. J. Elisha Mitchell Soc., May: 35-43.

WHitford, W. G. and G. EtTershank.

1975. Factors affecting foraging activity in Chihuahuan desert harvester ants. Env. Entomol. 4(5): 689-696.

Whitford, W. G., P. Johinson, and J. Ramirez.

1976. Comparative ecology of the harvester ants Pogonomyrmex harhatus (F. Smith) and Pogonom!rmex rugosus (Emery). Insectes Sociaux 23(2): 112-132.

WiLl.ARD, J. AND H. CROWHLL.

1965. Biological activities of the harvester ant, Pogonomyrmex owlyeei, in central Oregon. J. Econ. Entomol. 58: 484-489. 

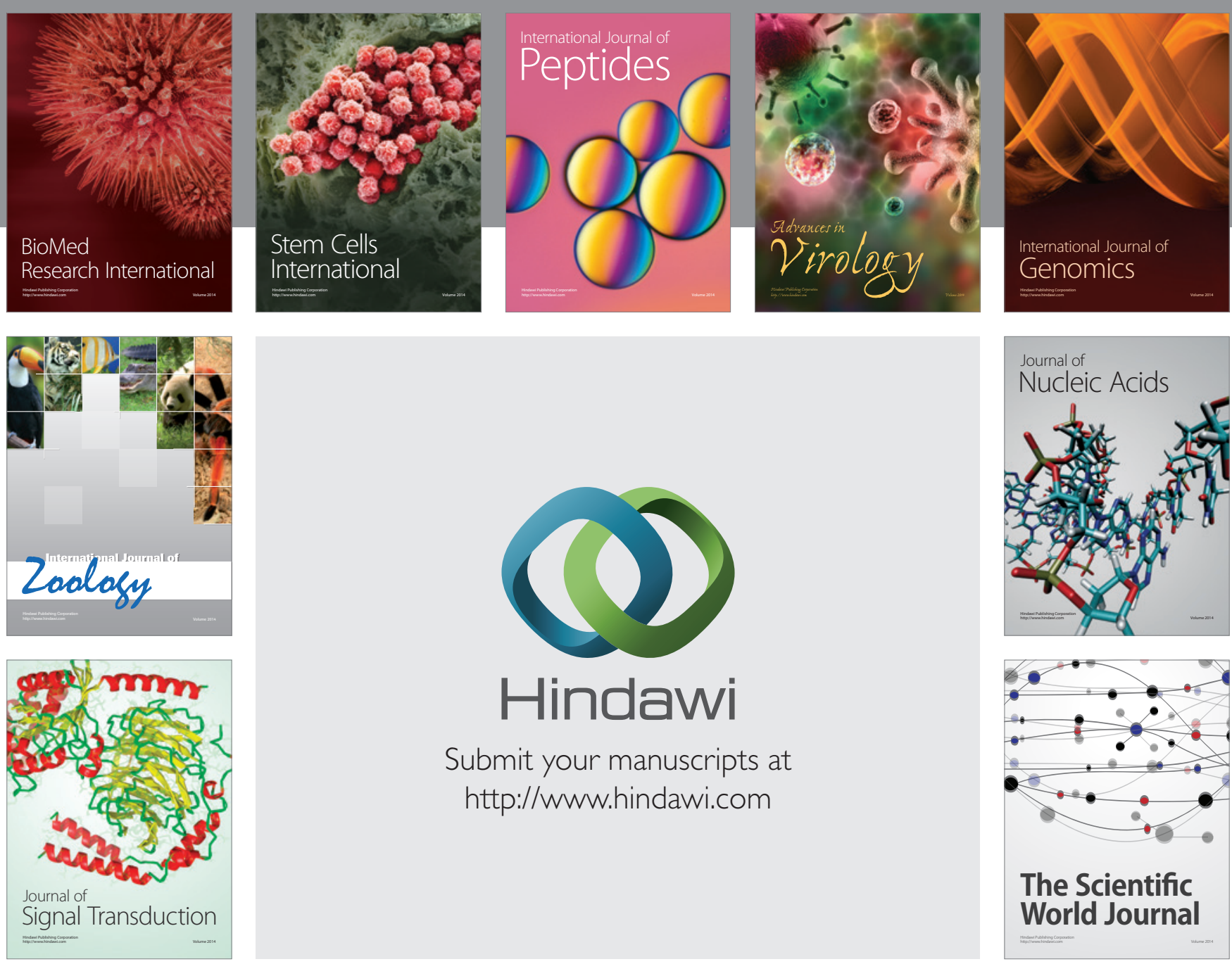

Submit your manuscripts at

http://www.hindawi.com
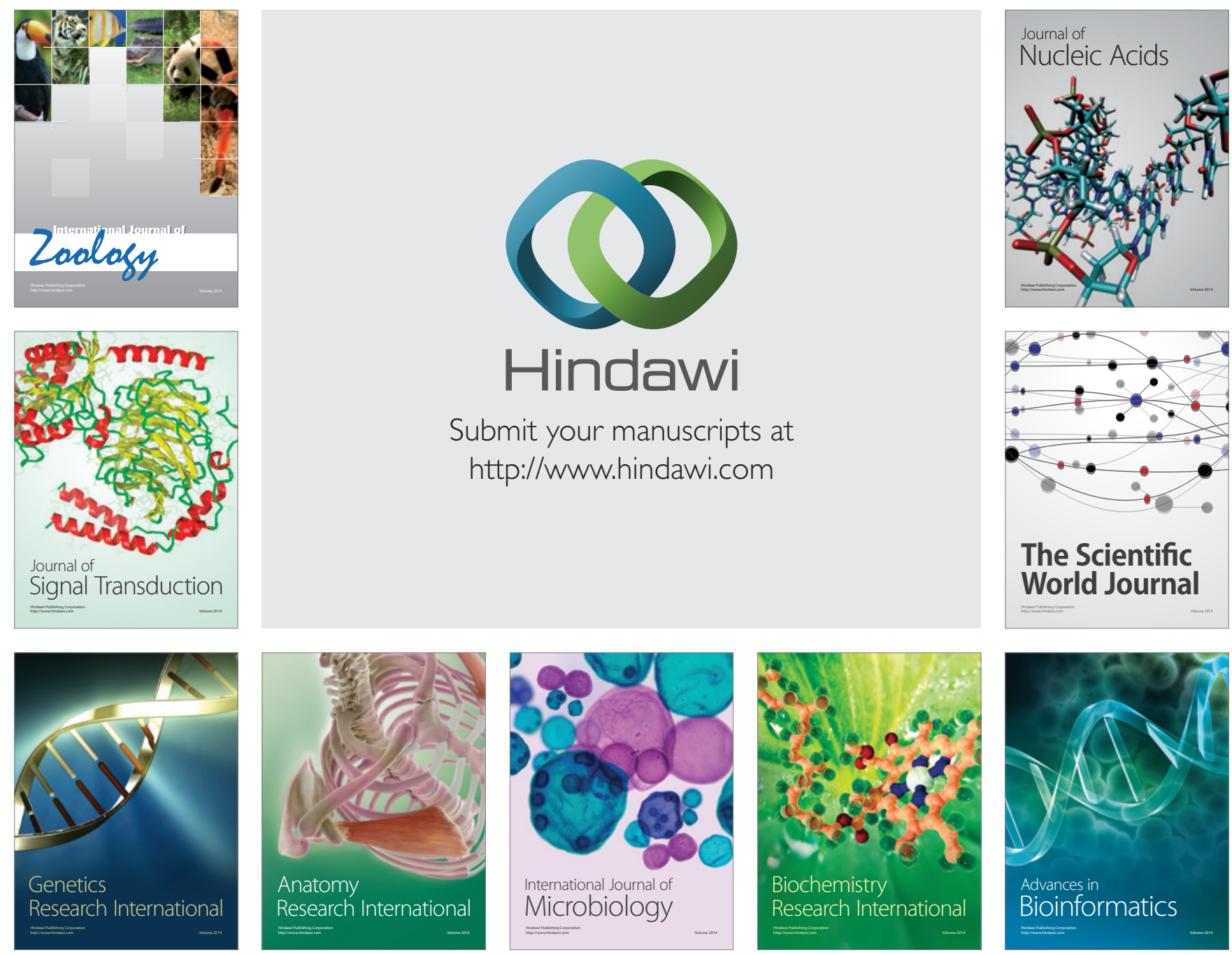

The Scientific World Journal
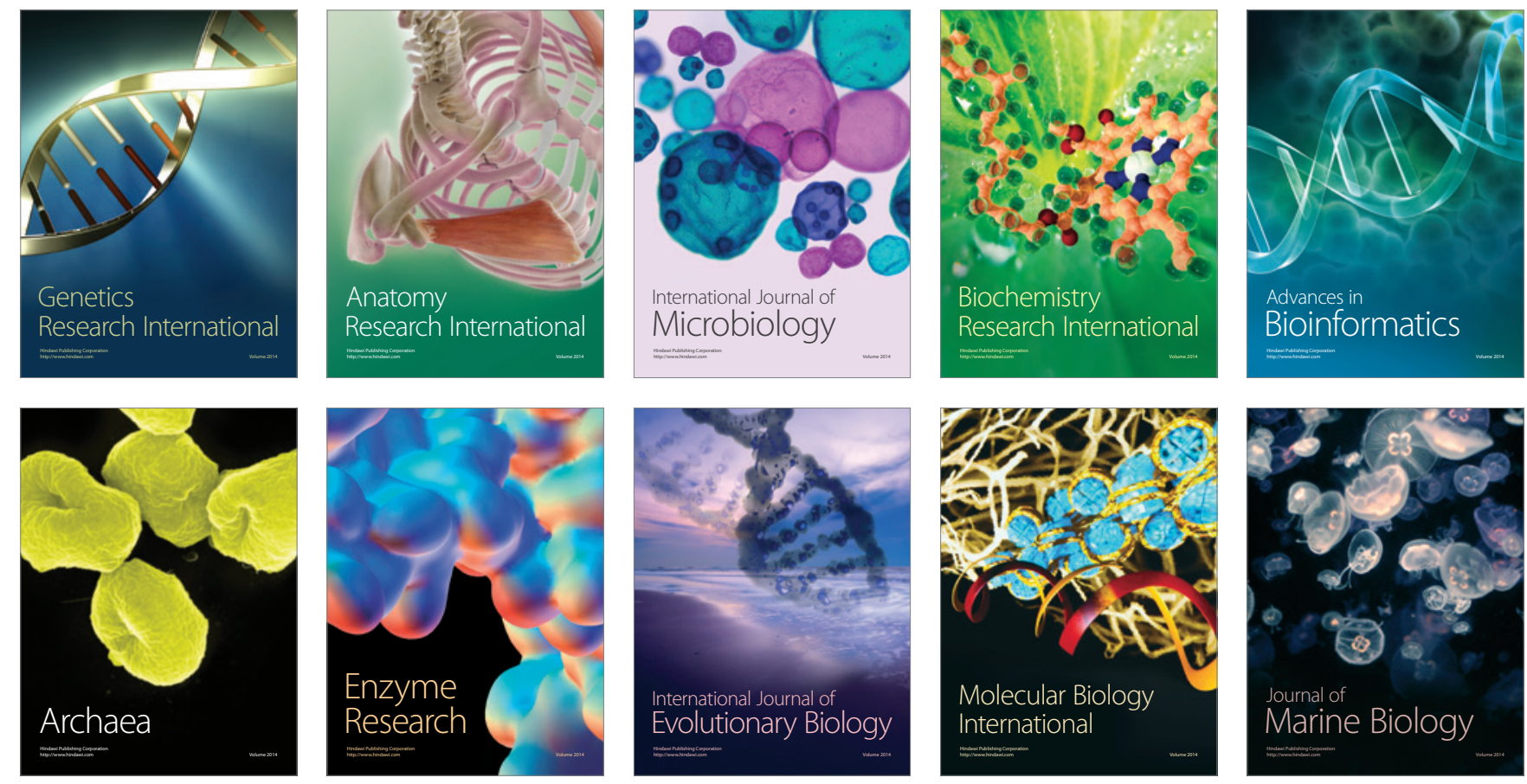